thinkers and their influence on physical education as well as their role in the determination of the form, objectives, curriculum, techniques of teaching, administration and discipline, etc. So that more effective schools become known and are utilised for making necessary policies and programmes leading to the development and bright future of physical education. Findings of this study, in short, are that no educational philosophy is complete in itself. Tendency of accumulation of the best of the various philosophies and principles is a specialty of physical education. The eminent educationist Ross has said 'If the goals of education are taken from the idealism and teaching methods and experimentation from naturalism and pragmatism. It would lead to the creation of the best educational philosophy'. From pre-primary and primary to the highest level we ought to adopt eclectic tendency to determine the educational objectives, curricula and methods, etc then only we can set-up an ideal and effective educational system and to train the citizens having good character and conduct, according to the democratic ideals we can establish a healthy, progressive, secularsociety and a prestigious democratic country.

\title{
250 AN ECLECTIC APPROACH TOWARDS PHYSICAL EDUCATION AND SCHOOLS OF PHILOSOPHY
}

Arvind Mishra Department of Physical Education, Allahabad Degree College, Allahabad, Uttar Pradesh, India

\subsection{6/bjsm.2010.078725.250}

Be it education, system or profession each has its own philosophy that gives direction to the policy determination, teaches how to use the acquired skills, knowledge, clarifies the values and beliefs. Physical education also has its own philosophy. In ancient period, the general form of the philosophy of physical education is visible in the social, political and spiritual life of that time and it's special form is visible in the branch of education in which efforts were made to educate both men as well as society.

In modern age the philosophy of physical education has broad perspective, from the philosophical point of view the study of sports, education, life, religion and science are united in the physical education. To express the philosophy of physical education all these are used as per requirement. In accordance with the time, condition and place, physical education also has been influenced by different philosophical schools. Consequently, the form of physical education has also been undergoing change. These schools have influenced differently all aspects of physical education, such as: aims, objectives, methods, curricula, teaching, discipline, administration, nature of the schools and organisations, etc.

The chief goal of the present study is to highlight the influence of various philosophical schools such as idealism, pragmatism, naturalism and realism, etc their origin, principles, leading 